\author{
多孔聚合物在锂金属负极保护中的研究进展 \\ 庄容 ${ }^{\dagger}, a$ 许潇酒 ${ }^{\dagger}, a$ 曲昌镇 $a$ 徐顺奇 $b \quad$ 于涛 $a$ \\ 王洪强 $*, a \quad$ 徐飞*,a \\ ( ${ }^{a}$ 西北工业大学 材料学院 凝固技术国家重点实验室 纳米能源材料研究中心 西安 710072) \\ ( ${ }^{b}$ 德累斯顿工业大学 化学与食品学院 德累斯顿 01062)
}

\begin{abstract}
摘要 锂金属负极具有极高的理论比容量和最低的还原电位, 因此锂金属电池被认为是最具潜力的高比能储能器件之 一. 然而, 充放电过程中不受控制的枝晶生长、不稳定的界面反应与巨大的体积变化导致锂金属负极库伦效率低与循 环稳定性差, 同时枝晶刺穿隔膜也会带来安全隐患, 这些问题极大地制约着锂金属电池的实际应用. 多孔聚合物由于 比表面积大、密度低、孔结构与微化学环境易裁剪等特点, 能够有效促进锂离子传输和均匀沉积, 已逐渐成为 “无枝 晶” 锂金属电池研究领域的 “新宠” . 然而, 相关的研究依然处于起步阶段, 本综述从人工固体电解质界面膜、隔膜修 饰层与锂负极结构设计三个方面对多孔聚合物在锂金属电池负极保护中的研究进行了介绍与评述.
\end{abstract}

关键词 锂金属电池; 锂枝晶; 负极保护; 多孔聚合物; 孔结构

\title{
Recent Progress of Porous Polymers for Lithium Metal Anodes Protection
}

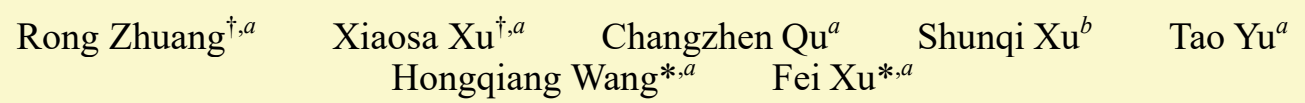

( ${ }^{a}$ State Key Laboratory of Solidification Processing, Center for Nano Energy Materials, School of Materials Science and Engineering, Northwestern Polytechnical University, Xi'an 710072, China)

$\left({ }^{b}\right.$ Faculty of Chemistry and Food Chemistry, Technische Universität Dresden, Dresden 01062, Germany)

Abstract Lithium metal batteries (LMBs) are regarded as one of the most promising candidates for next-generation high-energy-density devices, due to the high theoretical specific capacity and low electrochemical potential of lithium metal anode. However, the uncontrollable growth of $\mathrm{Li}$ dendrite, unstable $\mathrm{Li}$ /electrolyte interface and infinite volume fluctuation during charge/discharge process give rise to low Coulombic efficiency, poor cycle stability and even serious safety hazard from internal short-circuit via dendrite penetration through separators. These multifaceted problems severely hinder the practical applications of LMBs. Featured by high specific surface area, low density, controllable pore structure, and flexible molecular design of pore surface/skeleton functionality, porous polymers have received growing attention in electrochemical energy storage, especially for lithium anode protection. The nanopores and tailored functionalities could allow for facilitated $\mathrm{Li}$ ion transport, while inhibiting anions and regulating the grain size and distribution of $\mathrm{LiF}$. The large pores are conducive to accommodating lithium deposition and lowing of local current density. Consequently, porous polymers have become the "new favorite" in the field of "dendrite-free" LMBs recently, which show great potential for stabilizing Li metal anode. However, explorations in this field still remain in their infancy, and the objective of this review is to briefly summarize the research progress of porous polymers, especially crystalline covalent organic frameworks for lithium metal anodes protection, by means of constructing the artificial solid electrolyte interphase layer, coating separator with functional layers and designing metal anode structure.

Keywords lithium metal battery; Li dendrite; anode protection; porous polymer; pore structure

\section{1 引言}

随着电动汽车、便携式电子设备、大型储能网络等 行业的蓬勃发展, 高效电化学储能器件与相关材料的需
求日益增高. 然而, 目前基于石墨负极(理论比容量为 $372 \mathrm{mAh} \cdot \mathrm{g}^{-1}$ ) 的商用锂离子电池的能量密度已接近其理 论极限, 难以满足当代电动汽车等新兴行业对长续航、 高功率二次电池的需求. 因此, 开发具有新型高比能储

\footnotetext{
* E-mail: feixu@nwpu.edu.cn; Tel.: 029-88460684; Fax: 029-88460684

$\uparrow$ These authors contributed equally to this work

Received October 9, 2020; published November 18, 2020.

Project supported by the National Natural Science Foundation of China (Nos. 51702262, 51972270, 51872179, 51672225), the Natural Science Foundation of Shaanxi Province (No. 2020JZ-07) and the Key Research and Development Program of Shaanxi Province (No. 2019TSLGY07-03).

项目受国家自然科学基金(Nos. 51702262，51972270，51872179，51672225)、陕西省自然科学基金重点项目(2020JZ-07)和陕西省重点研发计划 (2019TSLGY07-03)资助.
} 


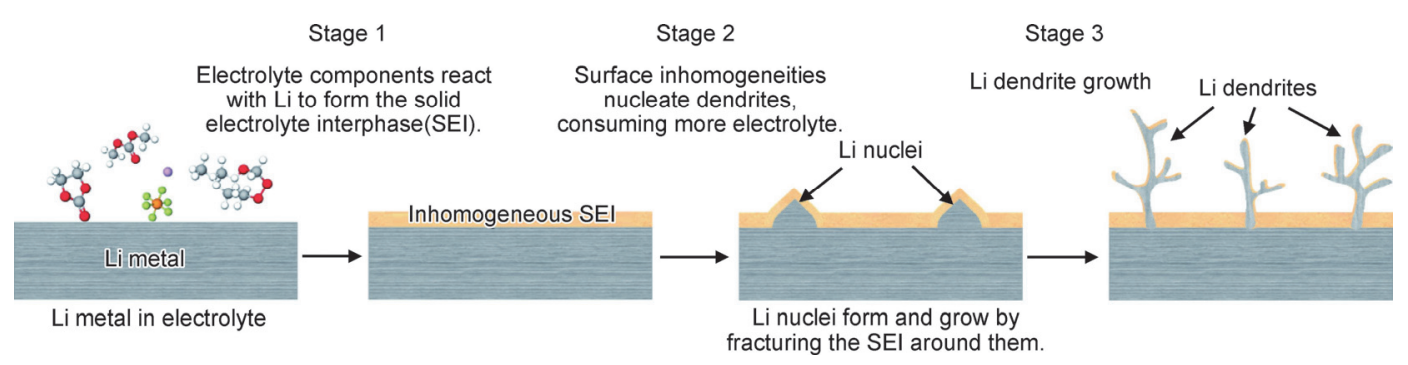

图 1 锂枝晶生长机理示意图 ${ }^{[4]}$

Figure 1 Mechanism illustration of Li dendrite growth ${ }^{[4]}$

能器件对于推动可持续社会的发展具有重大意义. 锂金 属电池中锂负极具有理论比容量高 $\left(3860 \mathrm{mAh} \cdot \mathrm{g}^{-1}\right)$, 电 化学电位低 $(-3.04 \mathrm{~V}$ vs. 标准氢电极) 和密度小 $(0.534$ $\left.\mathrm{g} \cdot \mathrm{cm}^{-3}\right)$ 的优势, 被视为最具潜力的下一代高比能电池 体系 ${ }^{[1]}$. 研究人员提出, 以锂金属为负极的新型锂金属 电池如锂硫电池和锂空气电池的理论能量密度分别高 达 2567 和 $3505 \mathrm{Wh} \cdot \mathrm{kg}^{-1}$, 具有极大实用价值 ${ }^{[2-3]}$. 然而, 由于锂金属反应活性高, 极易与电解液发生反应, 生成 不稳定的固体电解质界面(solid electrolyte interphases, $\mathrm{SEI}$, 导致内部的锂暴露在电解液中, 不可逆地消耗电 解质反复形成新的 SEI 膜, 致使电池的循环寿命和库伦 效率严重降低. 同时, 锂金属负极在充放电过程中会形 成大量枝晶(图 1) ${ }^{[4]}$, 极易刺穿隔膜, 使正负极相接导致 电池短路, 有可能引发火灾甚至爆炸, 造成严重的安全 隐患. 此外, 部分锂枝晶断裂后被 SEI 紧密包裏, 形成 “死锂”, 导致离子迁移受阻和界面电阻增加 ${ }^{[5]}$. 自 20 世纪七八十年代以来, 这些问题一直阻碍着锂金属电池 的实际应用 ${ }^{[6]}$.

近年来，随着材料设计、检测方法和表征技术的迅 速发展, 研究工作者对锂金属负极有了更深入的了解, 提出了多种锂枝晶成核和生长的模型(表面成核生长模 型、电荷诱导生长模型、SEI 扩散控制模型、沉积-溶解 模型和空间电荷模型等 $)^{[6-7]}$, 发展了诸多策略来稳定锂 金属负极,包括界面修饰(人工 SEI 膜和隔膜修饰

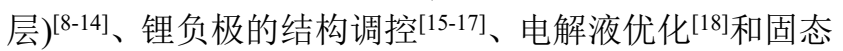
电解质 ${ }^{[19]}$ 等. 多孔聚合物由于比表面积高、密度低(由 C、 $\mathrm{H} 、 \mathrm{O} 、 \mathrm{~B} 、 \mathrm{~N}$ 等轻元素组成)、孔结构可调、表面与 骨架化学环境易裁剪等特点, 被广泛应用于催化、气体 储存与分离、光电功能材料、化学传感器与电化学储能

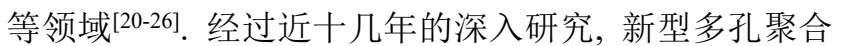
物得到了迅猛的发展, 主要包括共价有机框架材料

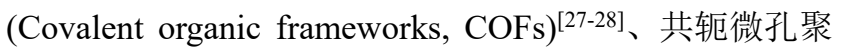
合物(Conjugated microporous polymers, CMPs) ${ }^{[29-30]}$ 、多 孔芳香框架聚合物 (Porous aromatic frameworks,

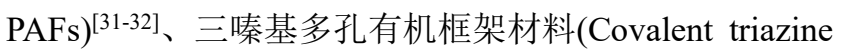

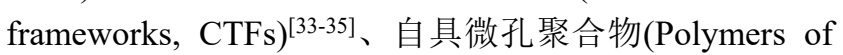
intrinsic microporosity, PIMs $)^{[36-37]}$ 和超交联微孔聚合物

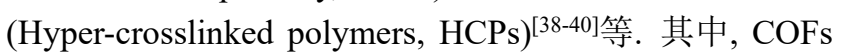
材料具有高度有序堆积排列的骨架、规则的孔道结构以
及易于分子设计调控等优点, 自 2005 年 Yaghi 小组 ${ }^{[27]}$ 报道首例 COF 以来, 研究人员相继开发出了多种具有 结构可调的 COFs 材料 ${ }^{[41-45]}$, 近两年来被应用于锂负极 的枝晶抑制 [46]. 本综述对近期多孔聚合物, 特别是 COFs 材料在锂金属负极保护方面的研究工作进行综述, 从设计人工 SEI 膜、隔膜修饰层以及锂负极结构三个方 面(图 2)展开, 并展望其未来的发展趋势.

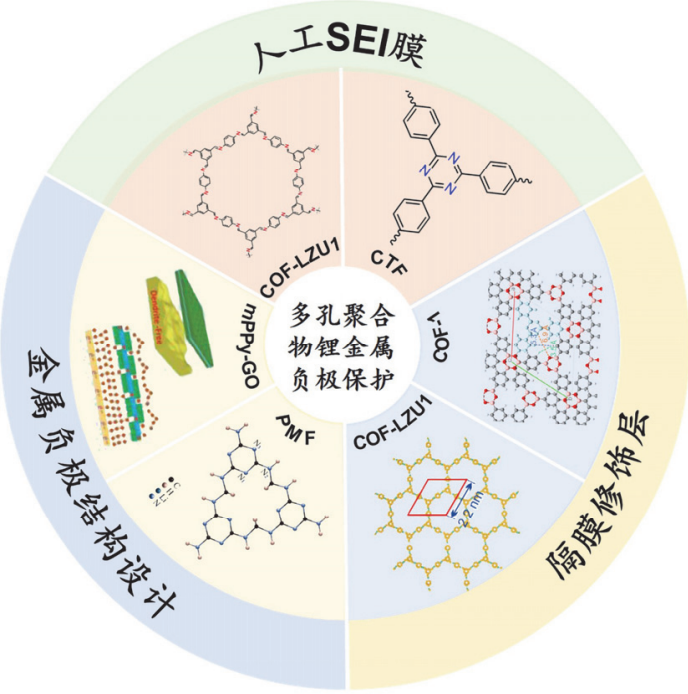

图 2 多孔聚合物在锂金属负极保护中的应用

Figure 2 The application of porous polymers for lithium metal anodes protection

\section{2 人工 SEI 膜改善锂金属负极}

有机液态电解质易与活泼金属锂发生反应，迅速生 成覆盖在电极表面的 SEI 膜. 其对锂负极的稳定起着至 关重要的作用. SEI 膜不仅可以阻止电解液与锂金属接 触发生不良反应，还可以促进 $\mathrm{Li}^{+}$的稳定沉积. 理想的 SEI 要求具有良好的均匀性、高度电子绝缘、高锂离子 电导率以及适当厚度和机械性能 ${ }^{[4,47]}$. 然而, 自然形成 的 SEI 结构不稳定, 在循环过程中不断地断裂、修复, 消 耗大量电解液，导致库伦效率降低以及形成 “死锂”, 电 池快速失效. 因此, 在锂金属表面生成稳定的人工 SEI 膜, 可以有效缓解锂枝晶的形成并提高锂负极的寿命. Meng 小组 ${ }^{[8]}$ 在锂金属表面原位制备厚度为 $10 \mathrm{~nm}$ 的 $\mathrm{COF}$ 薄膜作为人工 SEI 膜(图 3(a)). 在 COF 中引入电解 
质双三氟甲烷磺酰亚胺锂(Lithium bis((trifluoromethyl)sulfonyl)azanide, LiTFSI)后, LiTFSI 的 ${ }^{7} \mathrm{Li}$ 固体核磁化学 位移从 -1.80 移动到 -1.23 处, 研究认为, COF 中亲锂 亚胺基团可分离 LiTFSI 中的 $\mathrm{TFSI}^{-}$和 $\mathrm{Li}^{+}$, 有助于促进 $\mathrm{Li}^{+}$均匀沉积. 同时, 微孔结构还有利于电解液的浸润. 此外, 利用原子力显微镜分析表明超薄的 COF 膜表现 出较高的杨氏模量 $(6.8 \mathrm{GPa})$; 同时, 通过其探针模拟锂 枝晶刺穿的实验, 结果表明 COF 膜在 $379 \mathrm{nN}$ 的作用力 下维持弹性形变, 甚至在 $2.30 \mu \mathrm{N}$ 的作用力下仍不被刺 穿, 进一步证明 COF 薄膜具有较好的机械性能和力学 性能，能有效抵抗锂枝晶刺穿. 该方法对今后薄膜抑制 枝晶生长的研究有一定的参考价值. 该策略构筑了一个 薄而硬的微孔 COF 膜作为人工 SEI 膜, 在不影响 $\mathrm{Li}^{+}$传 导的前提下抑制了锂枝晶的产生. 采用对称电池研究发 现, 在电流密度为 $1 \mathrm{~mA} \cdot \mathrm{cm}^{-2}$ 、锂脱镀容量为 $1 \mathrm{mAh} \cdot$ $\mathrm{cm}^{-2}$ 的条件下, COF 保护的锂负极能够稳定运行 400 $\mathrm{h}$ (图 3(b)). 同年, Kang 小组 ${ }^{[9]}$ 采用 COF-LZU1 作为人工
SEI膜，基于路易斯酸碱理论，利用醛基与 $\mathrm{TFSI}^{-}$相互作 用，将 $\mathrm{TFSI}^{-}$固定在聚合物骨架上，削弱了空间电荷的 影响(图 3(c)), 提高了 $\mathrm{Li}^{+}$的迁移数 $(0.85)$, 并有利于 $\mathrm{Li}^{+}$ 的均匀分散. 通过红外和 $\zeta$ 电位测试证实了 COF-LZU1 可将电解质阴离子固定化. 因此, COF-LZU1 作为人工 SEI 膜, 有利于实现光滑均匀的、无枝晶的锂沉积. 将 COF-LZU1 涂覆在铜䇴上作为工作电极, 通过 $\mathrm{Li} \| \mathrm{Cu}$ 半 电池研究锂的沉积/剥离库伦效率, 其高于 $99.0 \%$; 此外, 将分散于 $N$-甲基-2-吡咯烷酮中的 COF-LZU1 滴在锂金 属表面, 得到厚度为 $75 \mu \mathrm{m}$ 的 COF-LZU1 修饰的锂电极, 组装 $\mathrm{Li} \| \mathrm{Li}$ 对称电池, 在 $0.5 \mathrm{~mA} \cdot \mathrm{cm}^{-2}$ 的电流密度下可运 行 $2000 \mathrm{~h}$ 以上; 以上述 COF-LZU1 修饰的金属锂为负极 组装锂硫电池, 在 $837 \mathrm{~mA} \cdot \mathrm{g}^{-1}$ 的电流密度下循环 300 圈 后, 放电比容量为 $635 \mathrm{mAh} \cdot \mathrm{g}^{-1}$ 、库伦效率为 $99.2 \%$, 改 善了电池的循环稳定性和倍率性能. 与自然形成的 SEI 膜相比，微孔聚合物人工 SEI 膜更加稳定，利用其自身
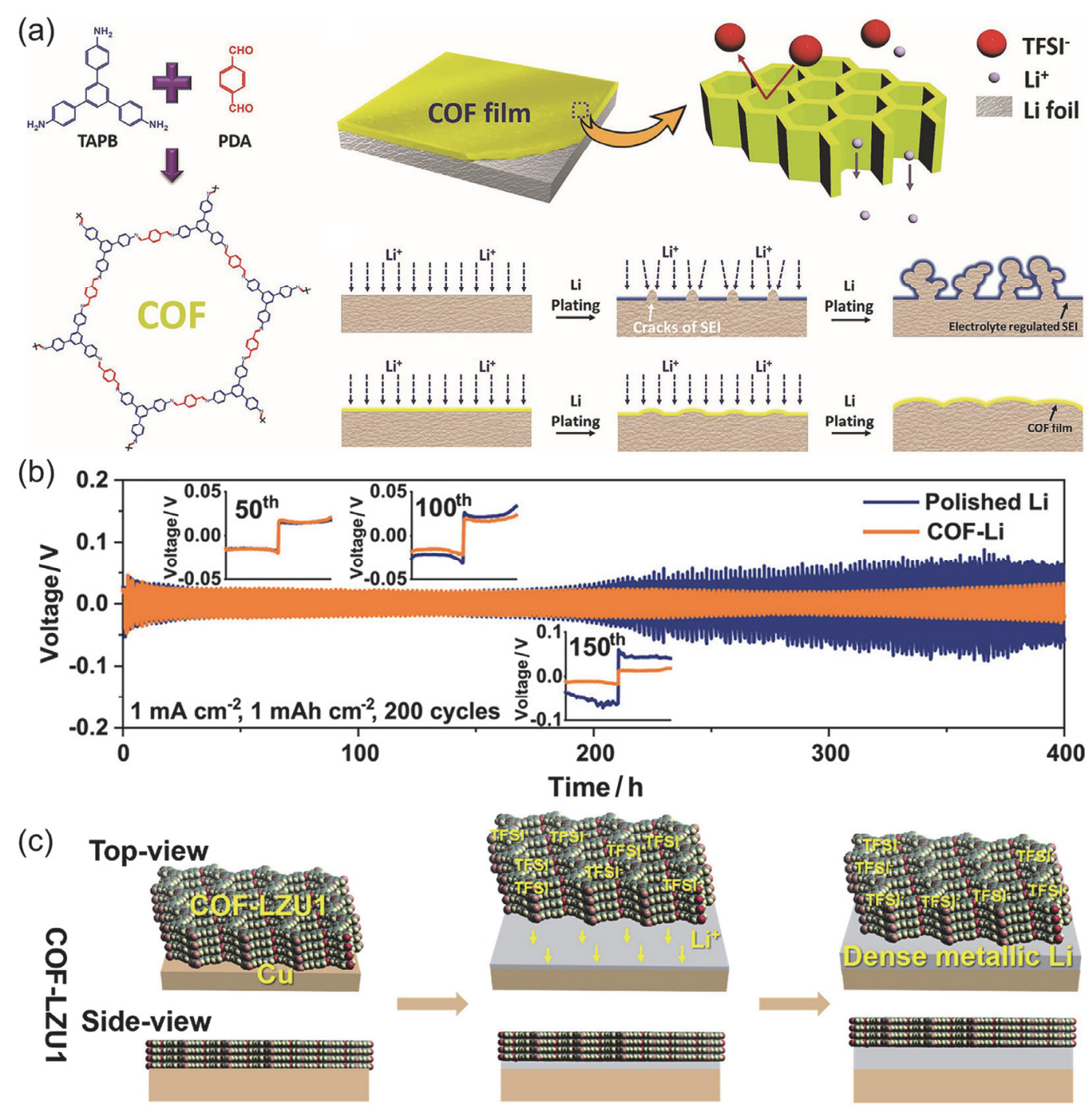

图 3 (a) COF 的制备过程以及锂沉积/脱镀示意图. (b) COF 保护锂负极在对称电池中的恒流循环图 ${ }^{[8]}$. (c) COF-LZU1 诱导锂沉积示意图 ${ }^{[9]}$

Figure 3 (a) Preparation scheme of COF and the schematic diagram of Li plating/stripping. (b) Galvanostatic cycling profile of polished Li and COF-Li in a symmetrical cell ${ }^{[8]}$. (c) Schematic of inducing Li deposition via COF-LZU1 ${ }^{[9]}$ 
结构特性, 提高了锂的利用率, 实现了锂的均匀沉积. 将修饰后的金属负极应用于锂金属电池时，从实际应用 角度来考虑, 负极容量/正极容量比 $(\mathrm{N} / \mathrm{P})$ 以及电解液的 用量至关重要.

为了满足实际应用中高能量密度的需求, 要求 $N / P$ 小于 2 以及电解液体积/负极容量比保持在 $10 \mu \mathrm{L}$ $\mathrm{mAh}^{-1}$ 以下 ${ }^{10]}$. 然而, 在大多数锂金属电池的相关报道 中, 长循环寿命的实现依赖于过量电解液的添加 $(>30$ $\left.\mu \mathrm{L} \cdot \mathrm{mAh}{ }^{-1}\right)$ 和较高的 $\mathrm{N} / \mathrm{P}$ 比 $(\mathrm{N} / \mathrm{P}>4)$, 导致电池质量增 加、能量密度降低以及生产成本增加, 限制锂金属电池 的实际应用 ${ }^{[48]}$. 最近, Guo 小组 ${ }^{[11]}$ 通过界面醛亚胺缩合 反应制备得到 $\beta$-酮胺连接的三种 $\mathrm{COF}$, 孔径从微孔到介 孔分别为 TpPa-COF (1.8 nm)、TpBD-COF 和 TpDATPCOF. 研究发现, TpPa-COF 薄膜具有最低的界面电阻和
最长的循环寿命. 并且研究了 $\mathrm{TpPa}-\mathrm{COF}$ 膜的最佳厚度 (80、180 和 $300 \mathrm{~nm}), 80 \mathrm{~nm}$ 的厚度就能有效抑制锂枝晶 生长. TpPa-COF 丰富的官能团赋予了其较高的 $\mathrm{Li}^{+}$亲和 性, 有助于从稀电解液中吸附锂盐, 经过电化学锂化之 后原位形成均匀分布的 LiF, 得到 COF-LiF 作为人工 SEI 膜(图 4(a)). 在极低 N/P 比(2.8)和贫电解液(12 $\mu \mathrm{L} \cdot \mathrm{mAh}{ }^{-1}$ ) 和高正极 $\mathrm{LiNi}_{0.5} \mathrm{Co}_{0.2} \mathrm{Mn}_{0.3} \mathrm{O}_{2}$ (NCM 523) 面容 量 $\left(3.8 \mathrm{mAh} \cdot \mathrm{cm}^{-2}\right)$ 的条件下, TpPa-COF 保护的锂金属作 为负极组装的全电池稳定循环 150 次后库伦效率依然为 $99.0 \%$ (图 4(b)). 在锂沉积容量为 $5 \mathrm{mAh} \cdot \mathrm{cm}^{-2}$ 时, 电流 密度为 $1 \sim 30 \mathrm{~mA} \cdot \mathrm{cm}^{-2}$, LiTpPa-LiF@Li 电极电压迟滞 趋于稳定, 展现出优异的电化学可逆性(图 4(c)). 研究 认为, 上述优异的电化学性能得益于以下三点: (1) COF 膜的同轴微孔通道 $(1.8 \mathrm{~nm})$ 能够限域生成 $\mathrm{LiF}$ 晶粒,

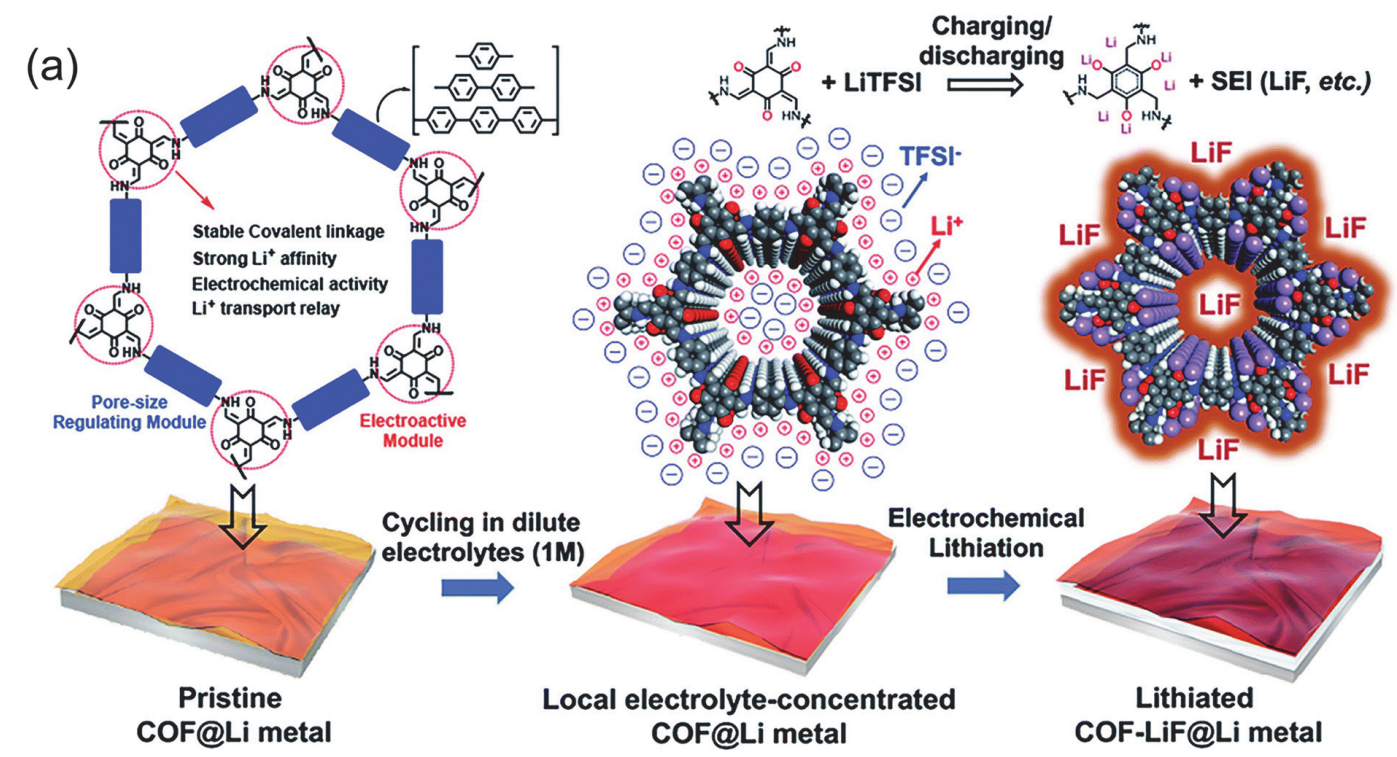

(b)

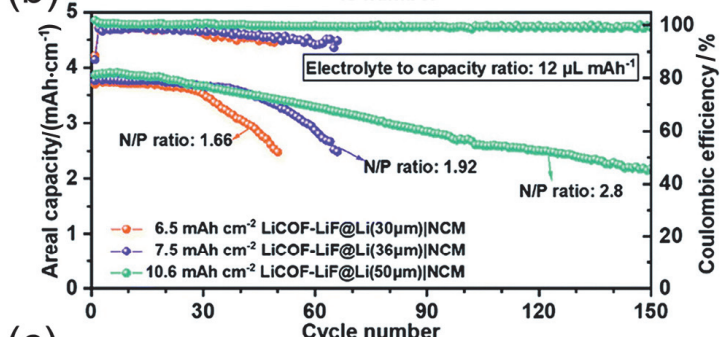

(c)

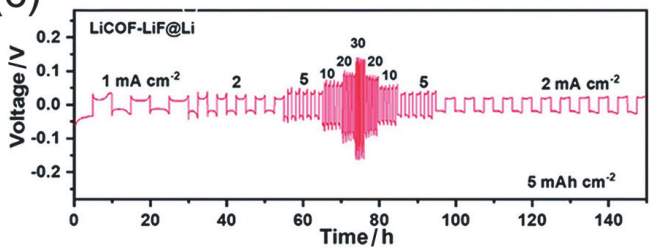

(d)

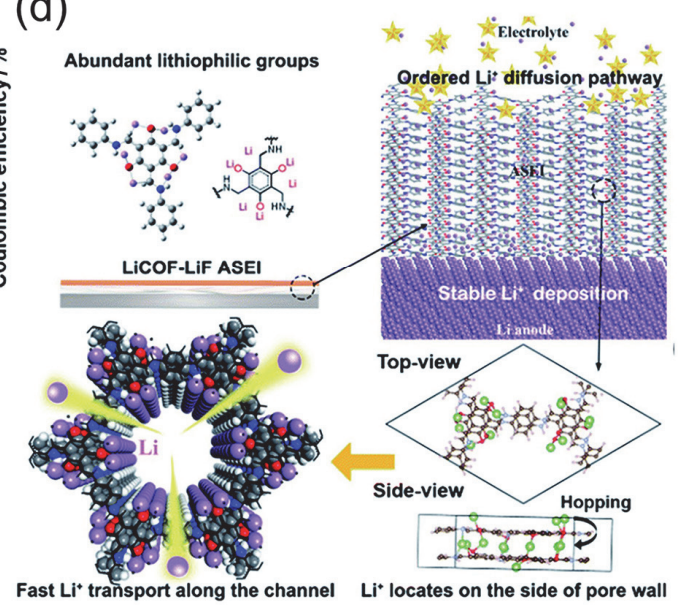

图 4 (a) COF-LiF 的电化学制备示意图. (b)在极低 N/P 比和有限电解液的条件下, LiCOF-LiF@Li|NCM 在 $0.15 \mathrm{C}$ 下的循环性能和库伦效率. (c)在 $1 \sim 30 \mathrm{~mA} \cdot \mathrm{cm}^{-2}$ 的电流密度和 $5 \mathrm{mAh} \cdot \mathrm{cm}^{-2}$ 的沉积容量下, LiCOF-LiF@ $\mathrm{Li}$ 的锂沉积/剥离图. (d)锂化 TpPa-COF 结构中 $\mathrm{Li}^{+}$的迁移过程示意图 ${ }^{[11]}$

Figure 4 (a) Schematic illustration of the electrochemical preparation of the COF-LiF hybrid interphase layer. (b) Cycling stability and coulombic efficiency of LiCOF-LiF@LilNCM at $0.15 \mathrm{C}$ under limited N/P ratios and electrolytes conditions. (c) Li deposition/dissolution profiles of LiCOF-LiF@Li at current densities from $1 \mathrm{~mA} \cdot \mathrm{cm}^{-2}$ to $30 \mathrm{~mA} \cdot \mathrm{cm}^{-2}$ with a deposition capacity of $5 \mathrm{mAh} \cdot \mathrm{cm}^{-2}$. (d) Schematic illustration of the fast $\mathrm{Li}^{+}$transport process through the optimized structures of the lithiated TpPa- $\mathrm{COF}^{[11]}$ 
使其均匀致密地分散在蜂窝状薄膜内部, 形成钝化表 面，可抑制循环过程中的副反应; (2) LiCOF-LiF 杂化界 面具有良好的机械性能(3.5 GPa), 几乎可以抵抗锂枝晶 的机械模量 $(2 \sim 4 \mathrm{GPa})$, 延缓了锂枝晶的生长; (3)通过 密度泛函理论(Density functional theory, DFT)模型进行 吸附能计算、 $\zeta$ 电位以及拉曼测试表明, TpPa-COF 对 $\mathrm{Li}^{+}$具有较高的亲和性, 使其在电场作用下沿着 $1 \mathrm{D}$ 孔壁 有序扩散, 加速了 $\mathrm{Li}^{+}$迁移 $\left(t_{\mathrm{Li}+}=0.79\right)$, 促进了锂均匀沉 积(图 4(d)). 在人工 SEI 膜中引入具有宽带隙、良好稳 定性和机械性能的钝化化合物 $\mathrm{LiF}$, 增强 $\mathrm{Li}^{+}$的扩散, 有 助于稳定锂负极 ${ }^{[49]}$. 上述 $\mathrm{LiF}$ 的引入需要额外在醚类电 解液中预先锂化制备得到, Coskun 小组 ${ }^{[12]}$ 通过 LiTFSI 锂盐催化氧基三聚实现了共价三嗪骨架原位生长 $\mathrm{LiF}(\mathrm{CTF}-\mathrm{LiF})$ 的构筑, 再将其负载到无尘纸(AP)上形成 复合电极 (AP-CTF-LiF). 通过测试发现 $m(\mathrm{CTF})$ : $m(\mathrm{LiF})$ 质量之比为 $3.3: 1$. 此外, 元素分析显示, CTF-LiF 中氮元素含量高达 $19.72 \%$, 具有良好的亲锂 性. 复合电极在 $10 \mathrm{~mA} \cdot \mathrm{cm}^{-2}$ 的高电流密度和 $1 \mathrm{mAh}$ $\mathrm{cm}^{-2}$ 的锂脱镀容量下循环 220 圈后库伦效率仍为 $96.2 \%$; 在 $1 \mathrm{mAh} \cdot \mathrm{cm}^{-2}$ 和 $5 \mathrm{~mA} \cdot \mathrm{cm}^{-2}$ 条件下, $\mathrm{Li} \| \mathrm{Li}$ 对称 电池可稳定循环 700 圈; 以 $3 \mathrm{mAh} \cdot \mathrm{cm}^{-2}$ 的面容量预锂 化的 AP-CTF-LiF 为负极, 与 $0.8 \mathrm{mg} \cdot \mathrm{cm}^{-2}$ 硫负载量的硫 @ 石墨烯正极组装锂硫电池, 在 $1 \mathrm{C}$ 下循环 375 圈后容 量保持率为 $42.1 \%$, 高于以 $\mathrm{AP}$ 和 $\mathrm{Cu}$ 为负极的锂硫电池. 研究表明, $\mathrm{LiF}$ 有助于形成稳定 SEI 膜, 无尘纸中具有足 够的储锂空间, 高氮含量的微孔聚合物 CTF-1 具有亲锂 性, 三者的协同作用提高了复合电极的电化学性能. 在 锂金属负极上构建有机多孔聚合物/无机杂化人工 SEI 膜(富含 $\mathrm{LiF}$ ) 为提高电池界面稳定性提供了新思路. 在 实际应用中, 人工 SEI 膜的厚度增加, 会增加电池的额 外质量, 降低能量密度, 也会影响 $\mathrm{Li}^{+}$传导以及锂的沉 积/剥离, 因此对成膜技术提出了更高的要求.

上述 COF 材料的孔径在微孔/小介孔范围内, 研究
者们进一步用介孔聚合物来保护锂金属负极，以实现均 匀的锂沉积, 得到无枝晶的锂金属电池. $\mathrm{Wu}$ 小组 ${ }^{[50]}$ 使 用硬模板策略, 得到具有较高机械强度、良好电解液浸 润性和结构稳定性的 $22 \mathrm{~nm}$ 介孔聚吡咯-氧化石墨烯二 维异质结构(mPPy-GO), 将其作为双功能锂离子再分配 器. 通过有限体积法模拟表明, 交错排列的介孔有利于 $\mathrm{Li}^{+}$的均匀分布(图 5(a)). mPPy-GO 电极在 $0.5 \mathrm{mAh}$ $\mathrm{cm}^{-2}$ 沉积容量和 $0.5 \mathrm{~mA} \cdot \mathrm{cm}^{-2}$ 的电流密度下循环 $2000 \mathrm{~h}$ (1000 圈), 库伦效率仍为 98.2\%(图 5(b)). 以预沉积 5 $\mathrm{mAh} \cdot \mathrm{cm}^{-2}$ 锂容量的 $\mathrm{mPPy}-\mathrm{GO}-\mathrm{Li}$ 作为负极, 以容量为 $0.3 \mathrm{mAh} \cdot \mathrm{cm}^{-2}$ 的 $\mathrm{LiCoO}_{2}$ 作为正极组装全电池, 循环 450 次后电池的容量保持率为 $92.0 \%$, 库伦效率接近 $100 \%$ (图 5(c)). DFT 模拟表明, 含有缺陷纳米孔的 GO 可 以作为降低 $\mathrm{Li}^{+}$穿梭速度的物理屏障, 从而延缓锂枝晶 的生长. 通过电化学测试对比, mPPy 的介孔阵列提供丰 富的纳米通道, 降低局部有效电流密度, 使 $\mathrm{Li}^{+}$均匀扩 散. 利用二者协同作用，实现均匀的锂离子通量，得到 稳定、无枝晶的锂金属负极. 二维介孔聚合物异质结构 设计和有机合成的三维微孔多孔炭材料为锂金属负极 保护提供了新的策略, 拓展了高能量密度碱金属电池负 极材料设计的思路.

\section{3 修饰隔膜改善锂金属负极}

除上述设计人工 SEI 膜以外，在负极构筑隔膜修饰 层也是一种常用的锂金属负极保护策略. 隔膜是电池的 重要组成部分, 具有阻挡电子流动、促进离子迁移的作 用，而商业化隔膜的多孔结构会在亚微米尺度上造成 $\mathrm{Li}^{+}$的不均匀沉积. 通过构筑隔膜修饰层的方法对其进 行调控，抑制锂枝晶的生长，从而得到高性能的锂金属 负极. Wang 小组 ${ }^{[13]}$ 提出了双层隔膜策略, 利用不同隔膜 的特性实现了对锂离子的连续去溶剂化与选择性传输, 抑制了锂的不均匀形核与枝晶生长(图 6(a)). 在该策略

(a)

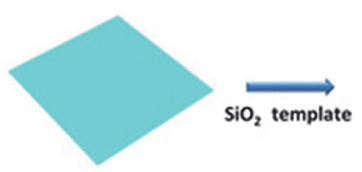

GO

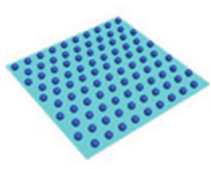

$\mathrm{SiO}_{2}-\mathrm{GO}$

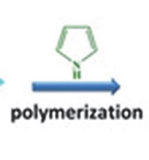

(c)
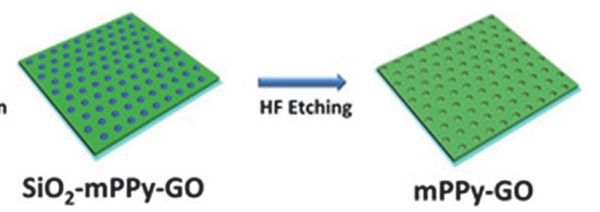

(b)
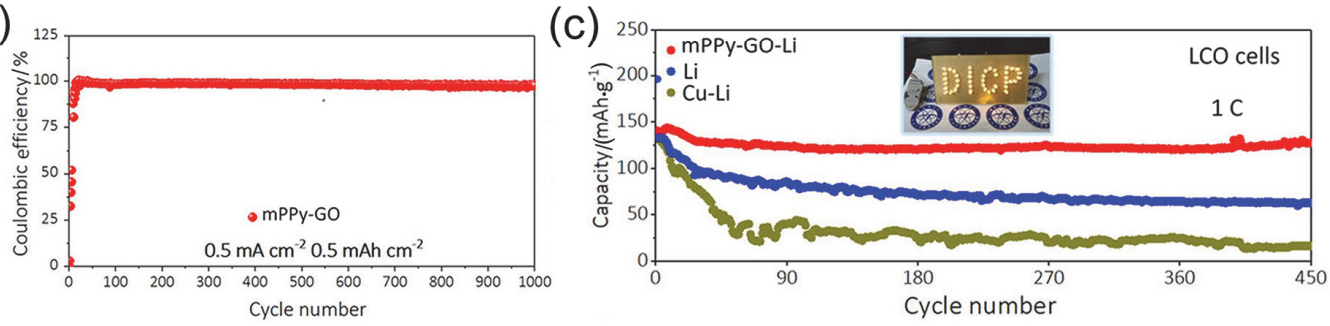

图 5 (a)二维 $\mathrm{mPPy}-\mathrm{GO}$ 异质结构的制备示意图. (b) $\mathrm{mPPy}-\mathrm{GO}$ 电极在电流密度为 $0.5 \mathrm{~mA} \cdot \mathrm{cm}^{-2}$ 和锂沉积容量为 $0.5 \mathrm{mAh} \cdot \mathrm{cm}^{-2}$ 时的库伦效率. (c) 以 $\mathrm{mPPy}-\mathrm{GO}-\mathrm{Li}$ 为负极, $\mathrm{LiCoO}_{2}$ 为正极所组装全电池的循环性能 ${ }^{[50]}$

Figure 5 (a) Schematic of the fabrication of 2D mPPy-GO heterostructure. (b) Ultralong time Coulombic efficiency test of mPPy-GO electrode with capacity of $0.5 \mathrm{mAh} \cdot \mathrm{cm}^{-2}$ at $0.5 \mathrm{~mA} \cdot \mathrm{cm}^{-2}$. (c) Long-term cycling stability of full batteries based on mPPy-GO-Li anode with LiCoO $\mathrm{mPathodes}^{[50]}$ 

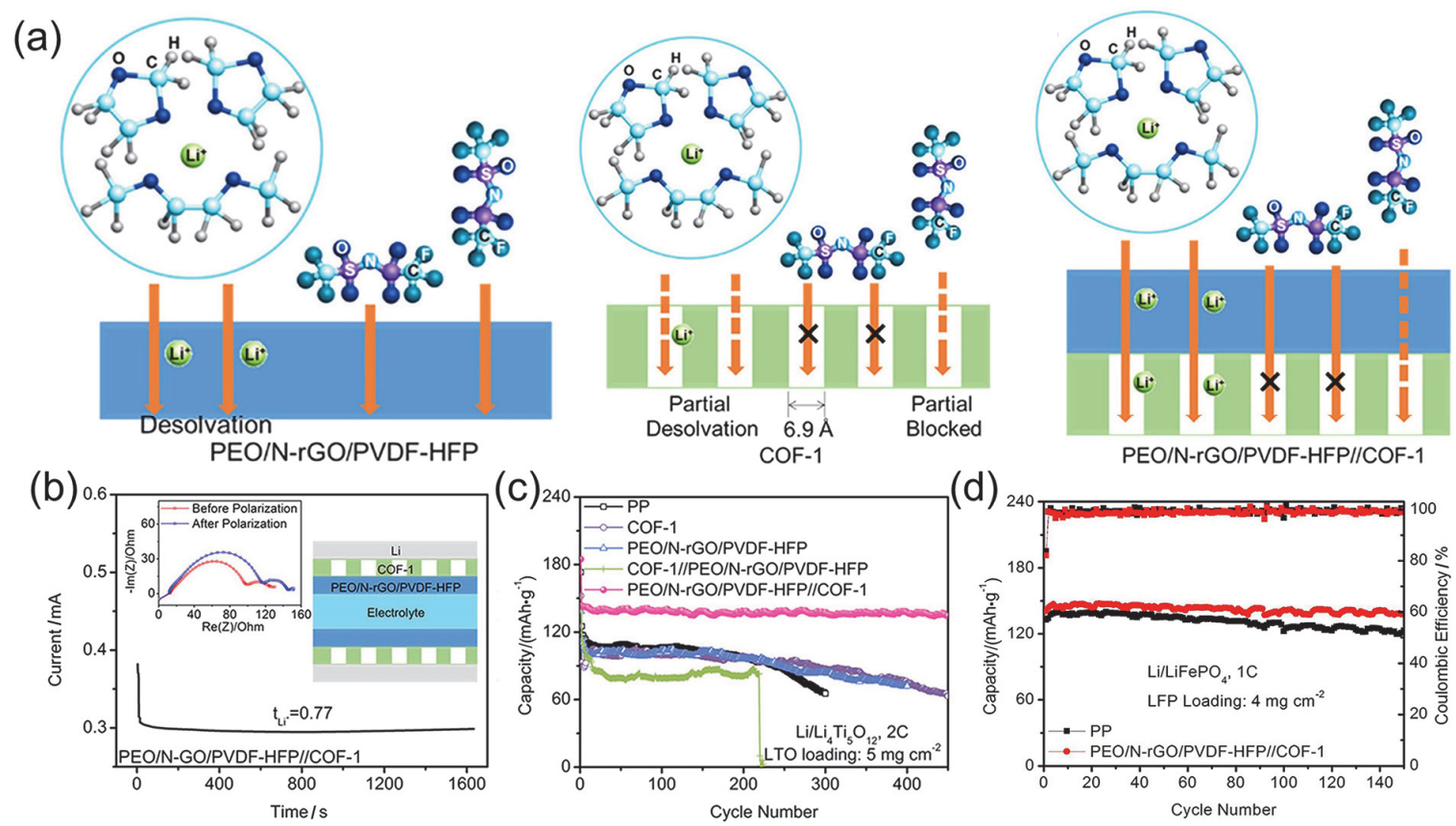

图 6 (a)溶剂化/去溶剂化 $\mathrm{Li}^{+}$、阴离子和阳离子通过不同隔膜的迁移示意图. (b) PEO/N-rGO/PVDF-HFP//COF-1 双层膜组装的 $\mathrm{Li}|| \mathrm{Li}$ 对称电池的 锂离子迁移数(内部插图为离子迁移数的测试电池示意图). (c) $\mathrm{Li}_{-}-\mathrm{Li}_{4} \mathrm{Ti}_{5} \mathrm{O}_{12}$ 全电池和(d) $\mathrm{Li}-\mathrm{LiFePO}_{4}$ 全电池的循环性能 ${ }^{[13]}$

Figure 6 (a) Schematic diagram of solvated/desolvated $\mathrm{Li}^{+}$and the transport of cations and anions through different membranes. (b) The Li-ion transference number of the $\mathrm{Li} \mid \mathrm{Li}$ cell with double-layer PEO/N-rGO/PVDF-HFP//COF-1 membrane (Inset of (b): the corresponding configuration of the cells for testing the ion transference number). The cycling performance of $\mathrm{Li}_{-}-\mathrm{Li}_{4} \mathrm{Ti}_{5} \mathrm{O}_{12}$ full battery (c) and $\mathrm{Li}-\mathrm{LiFePO}_{4}$ full battery (d) ${ }^{[13]}$

中，第一层膜为基于聚氧化乙烯(poly(ethylene oxide), $\mathrm{PEO})$ 基聚合物(PEO/N-rGO/PVDF-HFP), 第二层膜为有 序化排列的微孔聚合物 COF-1, 二者在 $6 \mathrm{MPa}$ 压力作用 下形成复合膜(PEO/N-rGO/PVDF-HFP//COF-1). 通过双 层隔膜的功能性集成, $\mathrm{Li}^{+}$迁移数高达 0.77 , 实现了均匀 沉积以及对锂枝晶的抑制(图 6(b)). 以复合膜为隔膜组 装 $\mathrm{Li} \| \mathrm{Cu}$ 半电池 $\left(\mathrm{COF}-1\right.$ 端对着 $\mathrm{Cu}$ ), 在 $0.5 \mathrm{~mA} \cdot \mathrm{cm}^{-2}$ 、 $0.5 \mathrm{mAh} \cdot \mathrm{cm}^{-2}$ 的锂脱镀电流密度与容量条件下, 展现出 高于其他隔膜(COF-1//PEO/N-rGO/PVDF-HFP 反向复合 膜、单层 COF-1 膜和单层 PEO/N-rGO/PVDF-HFP 膜) 的库伦效率 $(97.5 \%)$; 以上述双层复合膜为隔膜, 在 $\mathrm{Li}|| \mathrm{Li}$ 对称电池研究中 (COF-1 端对着 $\mathrm{Li})$, 在 $1 \mathrm{~mA}$ ・ $\mathrm{cm}^{-2} 、 1 \mathrm{mAh} \cdot \mathrm{cm}^{-2}$ 的锂脱镀电流密度与容量条件下能 够实现 $2200 \mathrm{~h}$ 的稳定循环. 同时, 在 $\mathrm{Li}_{4} \mathrm{Ti}_{5} \mathrm{O}_{12}$ 和 $\mathrm{LiFePO}_{4}$ 负载量分别为 $5 \mathrm{mg} \cdot \mathrm{cm}^{-2}$ 和 $4 \mathrm{mg} \cdot \mathrm{cm}^{-2}$ 的 $\mathrm{Li}-\mathrm{Li}_{4} \mathrm{Ti}_{5} \mathrm{O}_{12}$ 和 $\mathrm{Li}-\mathrm{LiFePO}_{4}$ 全电池体系中也表现出了较 高的比容量和优异的循环稳定性(图 6(c)和 6(d)). 研究 认为, $\mathrm{PEO}$ 与 $\mathrm{Li}^{+}$的结合能较高, 有利于提高 $\mathrm{Li}^{+}$的去溶 剂化效率, 但增加了 $\mathrm{Li}^{+}$通过 PEO 膜的势垒, 难以实现 $\mathrm{Li}^{+}$的选择性传输; 基于孔隙限制效应, 具有有序纳米 孔的 COF-1 膜(长宽为 $0.69 、 0.35 \mathrm{~nm}$ ) 可以阻挡除 $\mathrm{Li}^{+}$外 的其他组分 $\left(\mathrm{TFSI}^{-}\right.$, 长宽为 $0.75 、 0.36 \mathrm{~nm}$ ), 实现 $\mathrm{Li}^{+}$的 选择性运输和均匀沉积. $\mathrm{Ji}$ 小组 ${ }^{[14]}$ 采用微孔聚合物 $2 \mathrm{D}$ COF-LZU1 修饰聚丙烯(polypropylene, PP)隔膜负极侧, 利用 COF-LZU1 的纳米孔道 $(1.8 \mathrm{~nm}$ )模拟高尔顿板(图 $7(\mathrm{a})$ 和 7(b)), 迁移到锂金属表面的锂离子模拟小球, 提
高了 $\mathrm{Li}^{+}$的迁移数 $(0.77 \pm 0.01)$, 实现了 $\mathrm{Li}^{+}$的均匀分布, 抑制了锂枝晶的生长(图 7(c)). 与 $\mathrm{Li} / / \mathrm{PP} / / \mathrm{Li}$ 相比, COF-LZU1/PP 隔膜(厚度为 $5 \mu \mathrm{m}$ ) 修饰的 $\mathrm{Li}|| \mathrm{Li}$ 对称电池 $(\mathrm{Li} / / \mathrm{COF}-\mathrm{LZU} 1 / \mathrm{PP} / / \mathrm{Li})$ 在 $1 \mathrm{~mA} \cdot \mathrm{cm}^{-2} 、 1 \mathrm{mAh} \cdot \mathrm{cm}^{-2}$ 和 30 $\mu \mathrm{L}$ 电解液的条件下, 展现出了 $1000 \mathrm{~h}$ 的稳定循环和稳 定的电压迟滞(图 7(d)). 此外, 以 $\mathrm{LiFePO}_{4}$ 为正极 (3.8 $\mathrm{mg} \cdot \mathrm{cm}^{-2}$ )、锂金属为负极、COF-LZU1/PP 为隔膜组装 全电池, 在 $30 \mu \mathrm{L} \quad 1,3$-二氧戊环/乙二醇二甲醚 (DOL/DME)中循环 200 圈容量保持率为 $80 \%$. 微孔聚合 物在人工 SEI 膜、隔膜修饰层等界面修饰中的成功应用, 主要通过阻挡大尺寸阴离子的迁移和提高锂通量有效 抑制锂枝晶生长，提高锂金属负极的稳定性和安全性， 在一定程度上为下一代高能量密度电池铺平了道路.

\section{4 三维负极结构设计}

上述研究将微孔聚合物应用于隔膜修饰以稳定锂 负极的策略取得了一定的进展，但仍缺乏可储锂的大 孔. 因此, 合理设计三维大孔聚合物, 并在孔骨架上引 入亲锂基团/组分，一方面可以提供充足的锂沉积空间, 缓冲体积变化，同时也可以缓解局部电流密度分布不均 的情况, 对实现高电流密度下锂离子的均匀沉积具有重 大意义. 比如, Wang 小组 ${ }^{[15]}$ 设计出具有亲锂特性的三维 交联多孔聚乙烯-亚胺海绵(3D cross-linked porous polyethylenimine sponge, 3D PPS), 利用 PPS 对 $\mathrm{Li}^{+}$较强的亲 和力将其浓缩在海绵中(自浓缩特征), 使局部的 $\mathrm{Li}^{+}$浓 
(a)
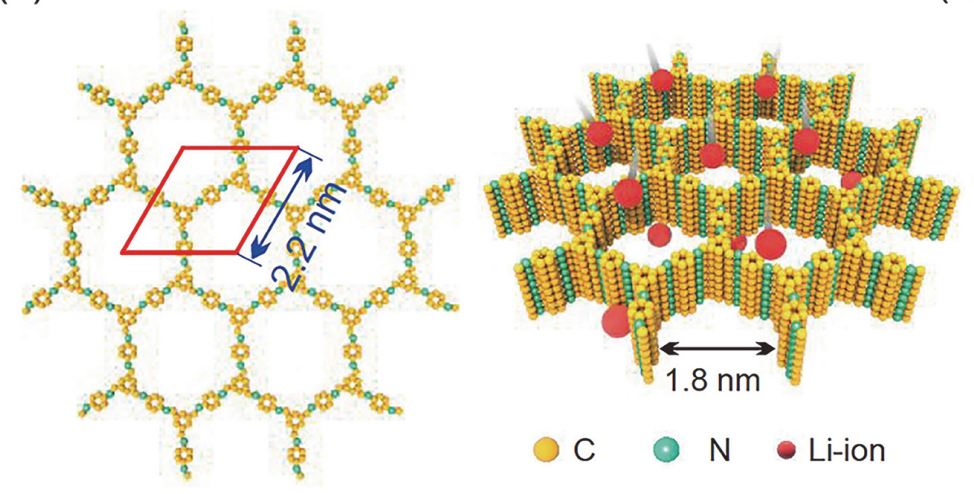

(b)

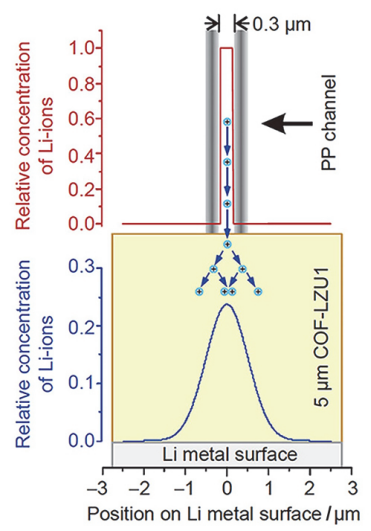

(c)

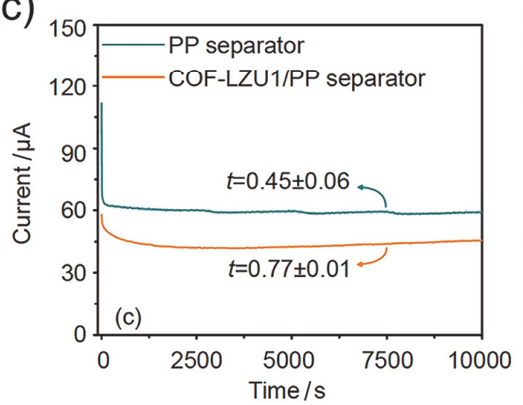

(d)
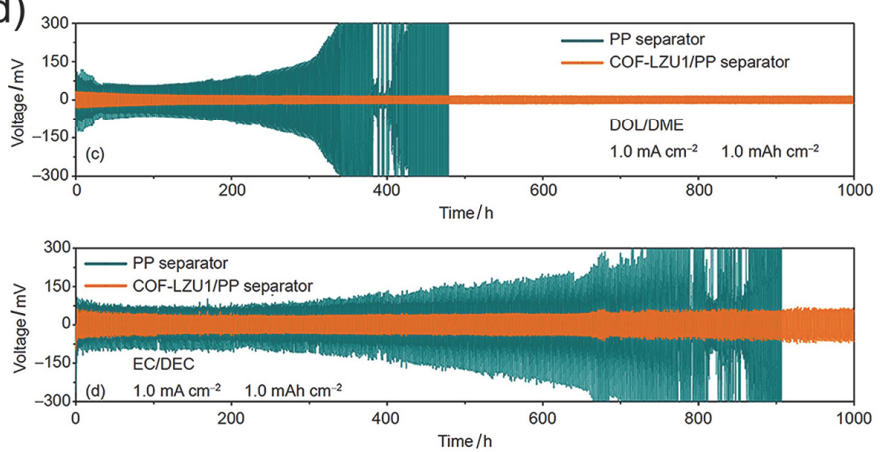

图 7 (a) COF-LZU1 的结构示意图和 $\mathrm{Li}^{+}$在 2D COF-LZU1 中的迁移图. (b) $\mathrm{Li}^{+}$遵循高尔顿板模型的沉积示意图. (c) $\mathrm{Li}^{+}$迁移数的测试. (d) 在不同 电解液体系中, 使用常规隔膜和 COF-LZU1/PP 隔膜的锂||锂对称电池的电化学性能对比 ${ }^{[14]}$

Figure 7 (a) Schematic of the structure of COF-LZU1 and Li-ion transport in the stacked 2D COF-LZU1. (b) Schematic of Li-ion deposition following the principle of Galton Board model. (c) Measurements of Li-ion transference numbers. (d) Comparison of electrochemical performance of Li $\mid \mathrm{Li}$ symmetric batteries with conventional separator and COF-LZU1/PP separator using different electrolyte ${ }^{[14]}$

度高于溶液(图 8(a)). 为了得到满足实际应用条件的全 电池，研究者以 $7.7 \mathrm{mAh} \cdot \mathrm{cm}^{-2}$ 的 $\mathrm{Li}$ 沉积在 3D PPS@Cu 为负极, 以高面积容量的 $\mathrm{LiFePO}_{4}\left(3.8 \mathrm{mAh} \cdot \mathrm{cm}^{-2}\right)$ 为正 极, 在 $\mathrm{N} / \mathrm{P}$ 比为 2 的条件下循环 400 次后库伦效率高达 99.78\%(图 8(b)). 测试结果表明, Li@3D PPS@Cu 负极 在实际应用条件下具有优异的循环稳定性. 研究认为, 具有不规则大孔以及高 $\zeta$ 电位的海绵可以利用电动表面 传导和电渗透功能提高 $\mathrm{Li}^{+}$传输速度, 改善 $\mathrm{Li}^{+}$的自浓缩 动力学, 改变电极表面锂离子浓度和电流密度分布. 3D PPS 利用自浓缩特性与电动表面传导的协同作用, 在高 电流密度和高沉积容量下, 实现了 $\mathrm{Li}^{+}$的均匀分布, 获 得高库伦效率、高面积比容量以及无枝晶的锂金属负极. 同年, $\mathrm{Lu}$ 小组 ${ }^{[16]}$ 设计出三维多孔聚三聚氧胺-甲醛泡沫 海绵(Porous poly-melamine-formaldehyde, PMF), 其表 面具有含氮极性基团, 与 $\mathrm{Li}^{+}$有较强的结合能, 可以促 进 $\mathrm{Li}^{+}$的均匀分布与形核, PMF 的三维结构可以作为沉 积载体, 抑制体积膨胀. 在三维大孔聚合物中设计导电 通道, 有望同时实现大倍率和高容量锂沉积/剥离, $\mathrm{Wu}$ 小组 ${ }^{[17]}$ 利用多孔三聚氰胺泡沫(Melamine foam, MF)的 柔性多孔特性, 在高电流密度和沉积容量下实现金属锂 的均匀沉积, 从而获得高性能锂金属负极. 将 MF 进一 步与导电 MXene 复合, 得到三维多孔导电网络(3D
MXene-MF)(图 8(c)). DFT 计算表明，表面的 O-、F-官能 团增加了锂原子与 MXene 结合能, MXene 表面化学的 调控提高了三维骨架的亲锂性. 有限单元法计算显示, 与 $\mathrm{Cu}$ 电极相比, $3 \mathrm{D}$ MXene-MF 电极实现了更高的 $\mathrm{Li}^{+}$ 浓度和较低的电流密度, 有利于锂均匀沉积. 对 $3 \mathrm{D}$ MXene-MF 电极在 $50 \mathrm{~mA} \cdot \mathrm{cm}^{-2}$ 的高电流密度和 50 $\mathrm{mAh} \cdot \mathrm{cm}^{-2}$ 的锂沉积容量下进行电化学测试, 库伦效率 高达 99\%(图 8(d)); 以 MXene-MF-Li 为电极的对称电池 在 $10 \mathrm{~mA} \cdot \mathrm{cm}^{-2}$ 电流密度和 $10 \mathrm{mAh} \cdot \mathrm{cm}^{-2}$ 的锂沉积容量 下具有 $3800 \mathrm{~h}$ (1900 圈)的长循环寿命(图 8(e)), 高于其 他文献报道; 用于软包电池 (MXene-MF-Li/MXeneMF-S)和扣式电池(MXene-MF-Li/S)同样表现出良好的 倍率性能和循环性能. 三维大孔聚合物在锂金属负极电 极结构设计中的成功应用, 对不同的电池体系 $(\mathrm{Na} 、 \mathrm{~K})$ 具有一定的普适性, 比如, Na/MXene-MF 电极在 10 $\mathrm{mA} \cdot \mathrm{cm}^{-2}$ 和 $10 \mathrm{mAh} \cdot \mathrm{cm}^{-2}$ 条件下循环 150 圈库伦效率为 $99 \%$; 以 MXene-MF-Na 为电极的对称电池在 $20 \mathrm{~mA}$ $\mathrm{cm}^{-2}$ 和 $20 \mathrm{mAh} \cdot \mathrm{cm}^{-2}$ 条件下仅有 $15 \mathrm{mV}$ 电压极化; MXene-MF-Na/ $\mathrm{Na}_{3} \mathrm{~V}_{2}\left(\mathrm{PO}_{4}\right)_{3}$ 电池在 $15 \mathrm{C}$ 下具有 84 $\mathrm{mAh} \cdot \mathrm{g}^{-1}$ 的容量, 展现出良好的电化学性能. 因此, 设 计导电三维大孔聚合物结构有望进一步激发多孔聚合 物在先进碱金属电池枝晶抑制方面的应用潜力. 

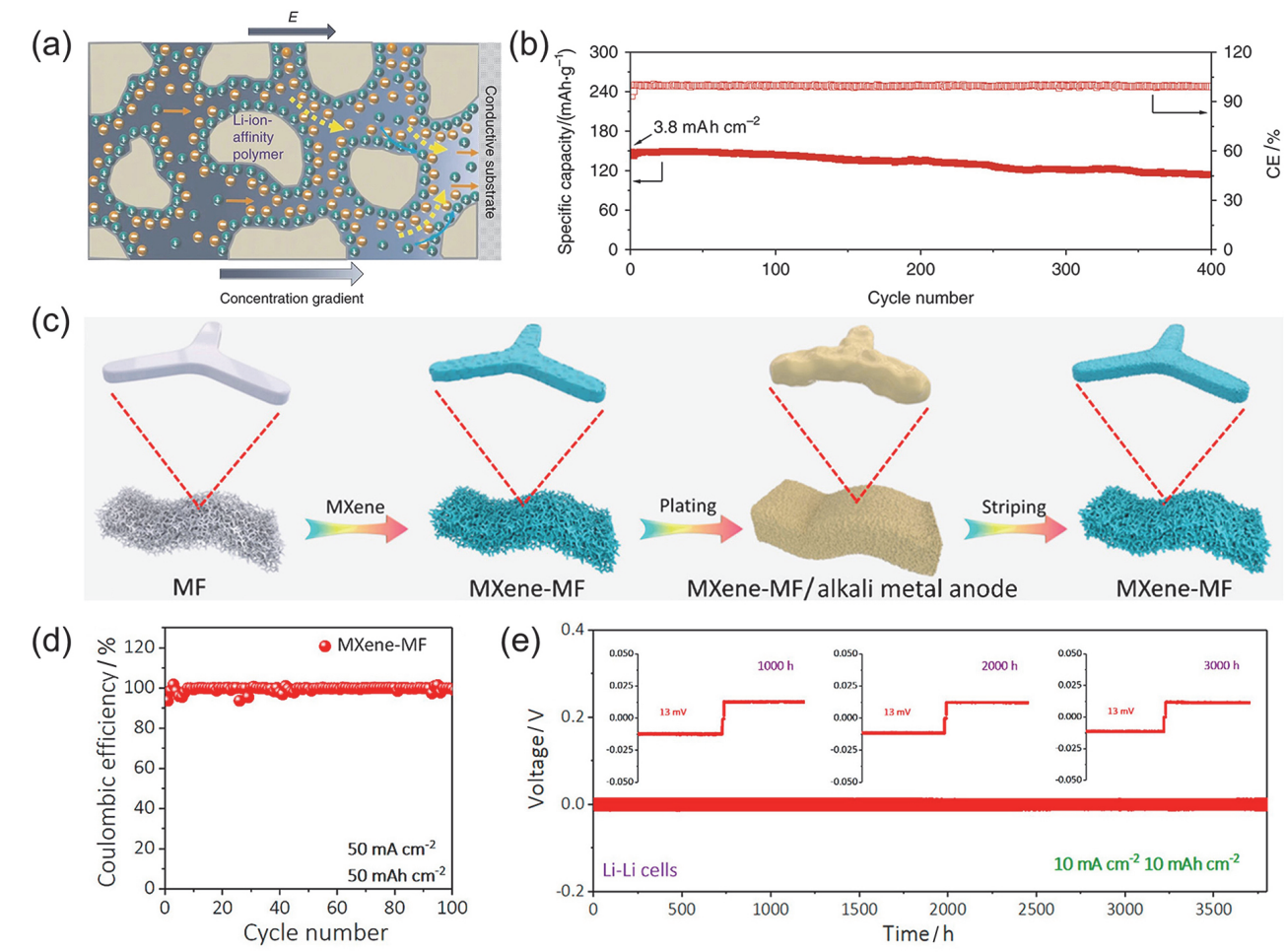

图 8 (a) 3D PPS 在电场中的电动效应. (b)以 $\mathrm{Li} @ 3 \mathrm{D}$ PPS@ $@ \mathrm{Cu}$ 为负极, $\mathrm{LiFePO}_{4}$ 为正极所组装全电池的循环性能 ${ }^{[15]}$. (c)用于碱金属负极的三维 MXene-MF 制备流程图. (d) 3D MXene-MF 电极在电流密度为 $50 \mathrm{~mA} \cdot \mathrm{cm}^{-2}$ 和锂沉积容量为 $50 \mathrm{mAh} \cdot \mathrm{cm}^{-2}$ 时的库伦效率. (e)基于 MXene-MF-Li 电 极的对称电池在电流密度为 $10 \mathrm{~mA} \cdot \mathrm{cm}^{-2}$ 和锂沉积容量为 $10 \mathrm{mAh} \cdot \mathrm{cm}^{-2}$ 时的循环性能 ${ }^{[17]}$

Figure 8 (a) Electrokinetic phenomena in 3D PPS under an electric field. (b) Cycling performance of full cells using Li@3D PPS@Cu as the anodes and a high-areal-capacity $\mathrm{LiFePO}_{4}$ as the cathodes ${ }^{[15]}$. (c) Schematic illustration of the fabrication process of 3D MXene-MF scaffold for alkali metal anode. (d) Coulombic efficiency of 3D MXene-MF electrode at high current density of $50 \mathrm{~mA} \cdot \mathrm{cm}^{-2}$ for $50 \mathrm{mAh} \bullet \mathrm{cm}^{-2}$. (e) Long-life symmetric cells galvanostatic cycling of MXene-MF-Li electrode at $10 \mathrm{~mA} \cdot \mathrm{cm}^{-2}$ with Li deposition capacity of $10 \mathrm{mAh} \cdot \mathrm{cm}^{-2[17]}$

\section{5 总结与展望}

本综述对过去三年中多孔聚合物在锂金属负极保 护中的研究进展和代表性工作进行了总结, 主要论述了 其在人工 SEI 膜、隔膜修饰层以及锂金属负极结构设计 方面的研究策略和作用机理, 如表 1 所示. 针对大电流 密度下锂枝晶的形成/生长引起的库伦效率低、循环性能 差以及安全性差等问题, 研究工作者以锂枝晶的成核和 生长模型为出发点, 从负极结构到界面等多个层面提供 了新的解决策略和设计思路, 主要对多孔聚合物孔结构 设计、表面化学调控、复合无机组分以及构筑三维结构 等方面的研究取得了一定的进展, 但是对于多孔聚合物 在锂金属负极保护方面仍存在诸多挑战:

(1)针对孔结构设计策略, 还需考虑如何平衡微孔/ 介孔/大孔结构设计, 实现孔结构的协同效应, 比如: 微孔可以通过孔隙限制效应等, 固定电解液阴离子和电 解液去溶剂化, 进而提高锂离子的迁移数; 介孔作为锂 离子传输通道, 实现均匀的锂沉积; 三维大孔提供容锂 空间, 抑制体积膨胀.

(2)针对表面化学调控策略, 可设计不同功能基团, 得到最佳基团并深入研究其如何辅助建立或参与形成 稳定 SEI 膜, 探索其深层机理, 将对多孔聚合物在锂金 属负极保护中的发展具有指导意义.
(3)将多孔聚合物与无机组分进行复合, 设计有机无机杂化界面，建立兼具机械强度和高分子柔性的界面 膜, 利用二者协同作用得到高锂离子电导率、高锂离子 迁移数和高稳定性的人工 SEI 膜.

(4)COF 薄膜的质量对锂金属电池的稳定性和实用 化至关重要, 不均匀将会造成局部电流密度过大, 进而 导致锂枝晶生长; 而厚度将会影响电池的质量、能量密 度以及锂离子的传导. 如何制备超薄、均匀性良好且具 备保护作用的 $\mathrm{COF}$ 薄膜, 仍存在极大挑战.

(5) 关于全电池的匹配问题尚未解决，尤其是实用 条件下的研究还很少(较低 N/P、贫电解液和超薄锂金属 负极), 比如匹配正极 $\left(\mathrm{LiFePO}_{4} 、 \mathrm{LiNi}_{1-x-y} \mathrm{Co}_{x} \mathrm{Mn}_{y} \mathrm{O}_{2}\right)$ 、锂 硫电池、锂空气电池、锂二氧化碳电池等, 也是未来努 力的方向.

(6)在新材料科学、表征和检测技术迅速发展的背景 下, 原位机理与理论模型研究仍需进一步探索, 比如 $\mathrm{Li}$ 在 COF 膜的传输行为、SEI 膜组分演变、枝晶原位生长 机制和临界电流密度等.

目前, 锂金属负极保护仍处于研究阶段, 多数方法 仍处于理论层面, 对于多孔聚合物在隔膜、SEI 膜和负 极结构设计方面的策略还需要进一步探索, 以开发出 更稳定高效的储锂体系，推动碱金属电池的实际应用. 
表 1 多孔聚合物应用于锂金属负极保护中的电化学性能

Table 1 The electrochemical performance of porous polymer in lithium metal anodes protection

\begin{tabular}{|c|c|c|c|c|c|}
\hline 材料 & $\begin{array}{l}\text { 电 流 密度/ } \\
\left(\mathrm{mA} \cdot \mathrm{cm}^{-2}\right)\end{array}$ & 容量 $\left(\left(\mathrm{mAh} \bullet \mathrm{cm}^{-2}\right)\right.$ & 电解液 & 循环寿命 & 参考文献 \\
\hline $\mathrm{COF}$ & 1 & 1 & $1 \mathrm{~mol} / \mathrm{L}$ LiTFSI in DOL/DME $(1: 1, V / V)$ & $400 \mathrm{~h}$ & [8] \\
\hline COF-LZU1 & 0.5 & 0.5 & $\begin{array}{c}1 \mathrm{~mol} / \mathrm{L} \text { LiTFSI in DOL/DME }(1: 1, V / V) \\
\text { with } 1 \%(w) \mathrm{LiNO}_{3}\end{array}$ & $2000 \mathrm{~h}$ & [9] \\
\hline $\mathrm{TpPa}-\mathrm{COF}$ & 10 & 5 & $\begin{array}{c}1 \mathrm{~mol} / \mathrm{L} \text { LiTFSI in DOL/DME }(1: 1, V / V) \\
\text { with } 1 \%(w) \mathrm{LiNO}_{3}\end{array}$ & $200 \mathrm{~h}$ & [11] \\
\hline AP-CTF-LiF & 5 & 1 & $\begin{array}{c}1 \mathrm{~mol} / \mathrm{L} \text { LiTFSI in DOL/DME }(1: 1, V / V) \\
\text { with } 2 \%(w) \mathrm{LiNO}_{3}\end{array}$ & $280 \mathrm{~h}$ & [12] \\
\hline mPPy-GO & 5 & 1 & $\begin{array}{c}1 \mathrm{~mol} / \mathrm{L} \text { LiTFSI in DOL/DME }(1: 1, V / V) \\
\text { with } 1 \%(w) \mathrm{LiNO}_{3}\end{array}$ & $400 \mathrm{~h}$ & {$[50]$} \\
\hline $\begin{array}{l}\mathrm{PEO} / \mathrm{N}-\mathrm{rGO} / \mathrm{PVDF}-\mathrm{HF} \\
\mathrm{P} / / \mathrm{COF}-1\end{array}$ & 1 & 1 & $\begin{array}{c}1 \mathrm{~mol} / \mathrm{L} \text { LiTFSI in DOL/DME }(1: 1, V / V) \\
\text { with } 1 \%(w) \mathrm{LiNO}_{3}\end{array}$ & $2200 \mathrm{~h}$ & [13] \\
\hline 2D COF-LZU1 & 1 & 1 & $\begin{array}{c}1 \mathrm{~mol} / \mathrm{L} \text { LiTFSI in DOL/DME }(1: 1, V / V) \\
\text { with } 2 \%(w) \mathrm{LiNO}_{3}\end{array}$ & $1000 \mathrm{~h}$ & [14] \\
\hline 3D PPS & 4 & 2 & $\begin{array}{c}1 \mathrm{~mol} / \mathrm{L} \text { LiTFSI in DOL/DME }(1: 1, V / V) \\
\text { with } 1 \%(w) \mathrm{LiNO}_{3}\end{array}$ & $300 \mathrm{~h}$ & [15] \\
\hline PMF & 10 & 1 & $1 \mathrm{~mol} / \mathrm{L}$ LiTFSI in DOL/DME $(1: 1, V / V)$ & $50 \mathrm{~h}$ & [16] \\
\hline 3D MXene-MF & 10 & 10 & $\begin{array}{c}1 \mathrm{~mol} / \mathrm{L} \text { LiTFSI in DOL/DME }(1: 1, V / V) \\
\text { with } 1 \%(w) \mathrm{LiNO}_{3}\end{array}$ & $3800 \mathrm{~h}$ & [17] \\
\hline
\end{tabular}

\section{作者简介}

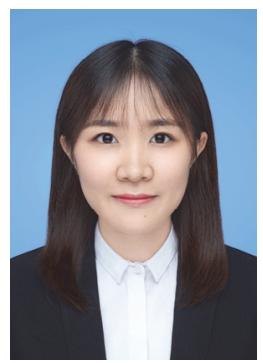

庄容, 2020 年毕业于北京化工大学, 获工学硕士学位, 目 前在徐飞副教授指导下攻读博士学位. 研究兴趣为 COFs 材料 的功能化设计与合成及其在储能方向的应用.

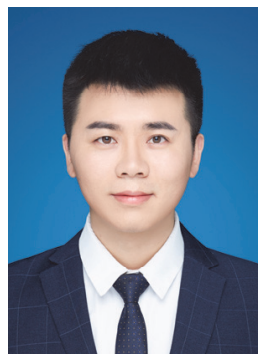

许潚酒, 2017 年毕业于陕西师范大学, 获工学硕士学位, 目前在王洪强教授和徐飞副教授指导下攻读博士学位, 研究 兴趣为纳米晶功能化的 COFs 材料及其储能性能研究.

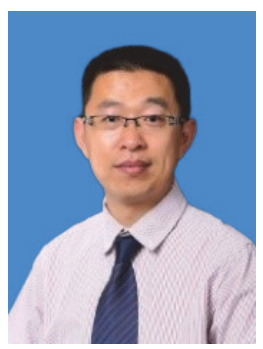

王洪强, 教授、博士生导师, 德国洪堡学者、欧盟玛丽居 里学者及国家高层次人才青年项目入选者. 2015 年加入西北
工业大学. 主要面向高性能钙钛矿光电器件、光电化学水分解 以及可充电电池等新能源器件用关键材料, 开展亚稳超纳材 料的瞬态极端制造与应用研究.

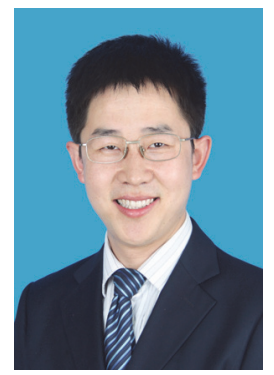

徐飞, 西北工业大学材料学院副教授、博士生导师、洪堡 学者, 于 2009 年和 2015 年在中山大学分别获得学士和博士学 位, 2012 2014 年在日本分子科学研究所从事联合培养博士 研究, 2018 2020 年在德累斯顿工业大学从事洪堡博士后研 究. 主要研究方向为功能多孔聚合物和炭材料的创新制备及 在电化学储能与吸附等领域的研究.

\section{References}

[1] Tikekar, M. D.; Choudhury, S.; Tu, Z.; Archer, L. A. Nat. Energy. 2016, 1,1 .

[2] Wang, M. Q.; Peng, Z.; Luo, W. W.; Ren, F. H.; Li, Z. D.; Zhang, Q.; He, H. Y.; Ouyang, C. Y.; Wang, D. Y. Adv. Energy Mater. 2019, 9, 1802912.

[3] Guo, Y. P.; Li, H. Q.; Zhai, T. Y. Adv. Mater. 2017, 29, 1700007.

[4] Qi, X.; Wang, C.; Nan, W. Z.; Hong, Q. H.; Peng, S. K.; Yan, S. J. J. Mater. Eng. 2020, 48, 50. (齐新, 王晨, 南文争, 洪起虎, 彭思㑆, 燕绍九, 材料工程, 2020, 48,50 .)

[5] Zhai, P.; Liu, L. X.; Gu, X. K.; Wang, T. S.; Gong, Y. J. Adv. Energy Mater. 2020, 10, 2001257.

[6] Liu, F. F.; Zhang, Z. W.; Ye, S. F.; Yao, Y.; Yu, Y. Acta Phys.-Chim. Sin. 2021，37，2006021. (刘凡凡，张志文，叶淑芬，姚雨，余彦， 物理化学学报, 2021, 37, 2006021.)

[7] Li, S.; Luo, Z.; Li, L.; Hu, J. G.; Zou, G. Q.; Hou, H. S.; Ji, X. B. Energy Storage Mater. 2020, 32, 306.

[8] Chen, D. D.; Huang, S.; Zhong, L.; Wang, S. J.; Xiao, M.; Han, D M.; Meng, Y. Z. Adv. Funct. Mater. 2020, 30, 1907717.

[9] Xu, Y.; Zhou, Y.; Li, T.; Jiang, S. H.; Qian, X.; Yue, Q.; Kang, Y. J. Energy Storage Mater. 2020, 25, 334.

[10] Gao, Y.; Yan, Z. F.; Gray, J. L.; He, X.; Wang, D. W.; Chen, T. H.; 
Huang, Q. Q.; Li, Y. C.; Wang, H. Y.; Kim, S. H.; Mallouk, T. E.; Wang, D. H. Nat. Mater. 2019, 18, 384.

[11] Zhao, Z. D.; Chen, W. J.; Impeng, S.; Li, M. X.; Wang, R.; Liu, Y. C.; Zhang, L.; Dong, L.; Unruangsri, J.; Peng, C. X.; Wang, C. C.; Namuangruk, S.; Lee, S. Y.; Wang, Y. G.; Lu, H. B.; Guo, J. J. Mater. Chem. A 2020, 8, 3459.

[12] Zhou, T. H.; Zhao, Y.; Choi, J. W.; Coskun, A. Angew. Chem., Int. Ed. 2019, 58, 16795.

[13] Jiang, C.; Gu, Y. M.; Tang, M.; Chen, Y.; Wu, Y. C.; Ma, J.; Wang, C. L.; Hu, W. P. ACS Appl. Mater. Interfaces 2020, 12, 10461.

[14] Xie, H. Y.; Hao, Q.; Jin, H. C.; Xie, S.; Sun, Z. W.; Ye, Y. D.; Zhang, C. H.; Wang, D.; Ji, H. X.; Wan, L. J. Sci. China: Chem. 2020, 63, 1306.

[15] Li, G. X.; Liu, Z.; Huang, Q. Q.; Gao, Y.; Regula, M.; Wang, D. W.; Chen, L. Q.; Wang, D. H. Nat. Energy. 2018, 3, 1076.

[16] Fan, L.; Zhuang, H. L.; Zhang, W. D.; Fu, Y.; Liao, Z. H.; Lu, Y. Y. Adv. Energy Mater. 2018, 8, 1703360.

[17] Shi, H. D.; Yue, M.; Zhang, C. J.; Dong, Y. F.; Lu, P. F.; Zheng, S. H.; Huang, H. J.; Chen, J.; Wen, P. C.; Xu, Z. C.; Zheng, Q.; Li, X. F.; Yu, Y.; Wu, Z. S. ACS Nano 2020, 14, 8678

[18] Fu, C.; Venturi, V.; Kim, J.; Ahmad, Z.; Ells, A.-W.; Viswanathan, V.; Helms, B. A. Nat. Mater. 2020, 19, 758.

[19] Lee, Y. G.; Fujiki, S.; Jung, C.; Suzuki, N.; Yashiro, N.; Omoda, R.; Ko, D. S.; Shiratsuchi, T.; Sugimoto, T.; Ryu, S. Nat. Energy. 2020, 5,348 .

[20] Das, S.; Heasman, P.; Ben, T.; Qiu, S. L. Chem. Rev. 2017, 117, 1515.

[21] Zheng, B. N.; Lin, X. D.; Zhang, X. C.; Wu, D. C.; Matyjaszewski, K. Adv. Funct. Mater. 2019, 30, 1907006.

[22] Sun, Q.; Dai, Z. F.; Meng, X. J.; Xiao, F. S. Chem. Soc. Rev. 2015, 44, 6018 .

[23] Wu, J. L.; Xu, F.; Li, S. M.; Ma, P. W.; Zhang, X. C.; Liu, Q. H.; Fu, R. W.; Wu, D. C. Adv. Mater. 2019, 31, 1802922.

[24] Wu, D. C.; Xu, F.; Sun, B.; Fu, R. W.; He, H. K.; Matyjaszewski, K. Chem. Rev. 2012, 112, 3959.

[25] Peng, Z. K.; Ding, H. M.; Chen, R. F.; Gao, C.; Wang, C. Acta Chim Sinica 2019，77，681. (彭正康，丁慧敏，陈如凡，高超，汪成，化 学学报, 2019, 77, 681.)

[26] He, Q.; Zhang, C.; Li, X.; Wang, X.; Mou, P.; Jiang, J. X. Acta Chim. Sinica 2018, 76, 202. (贺倩, 张崇, 李晓, 王雪, 牟攀, 蒋加 兴, 化学学报, 2018, 76, 202.)

[27] Côté, A. P.; Benin, A. I.; Ockwig, N. W.; O'Keeffe, M.; Matzger, A. J.; Yaghi, O. M. Science 2005, 310, 1166.

[28] Geng, K.; He, T.; Liu, R. Y.; Dalapati, S.; Tan, K. T. T.; Li, Z. P.; Tao, S. S.; Gong, Y. F.; Jiang, Q. H.; Jiang, D. L. Chem. Rev. 2020, 120,8814 .

[29] Jiang, J. X.; Su, F.; Trewin, A.; Wood, C. D.; Campbell, N. L.; Niu, H.; Dickinson, C.; Ganin, A. Y.; Rosseinsky, M. J.; Khimyak, Y. Z.
Angew. Chem., Int. Ed. 2007, 46, 8574.

[30] Xu, Y. H.; Jin, S. B.; Xu, H.; Nagai, A.; Jiang, D. L. Chem. Soc. Rev. 2013, 42, 8012 .

[31] Ben, T.; Ren, H.; Ma, S. Q.; Cao, D. P.; Lan, J. H.; Jing, X. F.; Wang, W. C.; Xu, J.; Deng, F.; Simmons, J. M.; Qiu, S. L.; Zhu, G. S. Angew. Chem., Int. Ed. 2009, 121, 9621.

[32] Tian, Y. Y.; Zhu, G. S. Chem. Rev. 2020, 120, 8934.

[33] Kuhn, P.; Antonietti, M.; Thomas, A. Angew. Chem., Int. Ed. 2008, 47, 3450 .

[34] Liu, M. Y.; Guo, L. P.; Jin, S. B.; Tan, B. J. Mater. Chem. A 2019, 7, 5153.

[35] Xu, F.; Yang, S. H.; Jiang, G. S.; Ye, Q.; Wei, B. Q.; Wang, H. Q. ACS Appl. Mater. Interfaces 2017, 9, 37731.

[36] Budd, P. M.; Ghanem, B. S.; Makhseed, S.; McKeown, N. B.; Msayib, K. J.; Tattershall, C. E. Chem. Commun. 2004, 230.

[37] Comesaña-Gándara, B.; Chen, J.; Bezzu, C. G.; Carta, M.; Rose, I.; Ferrari, M. C.; Esposito, E.; Fuoco, A.; Jansen, J. C.; McKeown, N. B. Energy Environ. Sci. 2019, 12, 2733.

[38] Wood, C. D.; Tan, B.; Trewin, A.; Niu, H.; Bradshaw, D.; Rosseinsky, M. J.; Khimyak, Y. Z.; Campbell, N. L.; Kirk, R.; Stöckel, E. Chem. Mater. 2007, 19, 2034.

[39] Tan, L. X.; Tan, B. Chem. Soc. Rev. 2017, 46, 3322.

[40] Rozyyev, V.; Thirion, D.; Ullah, R.; Lee, J.; Jung, M.; Oh, H.; Atilhan, M.; Yavuz, C. T. Nat. Energy. 2019, 4, 604.

[41] Liang, R. R.; Jiang, S. Y.; Ru-Han, A.; Zhao, X. Chem. Soc. Rev. 2020, 49, 3920.

[42] Rodríguez-San-Miguel, D.; Zamora, F. Chem. Soc. Rev. 2019, 48, 4375 .

[43] Sun, T.; Xie, J.; Guo, W.; Li, D. S.; Zhang, Q. C. Adv. Energy Mater. 2020, 10, 1904199.

[44] Xu, F.; Yang, S. H.; Chen, X.; Liu, Q. H.; Li, H. J.; Wang, H. Q.; Wei, B. Q.; Jiang, D. L. Chem. Sci. 2019, 10, 6001.

[45] Xu, F.; Xu, H.; Chen, X.; Wu, D. C.; Wu, Y.; Liu, H.; Gu, C.; Fu, R. W.; Jiang, D. L. Angew. Chem., Int. Ed. 2015, 127, 6918

[46] Wu, J. L.; Xu, F.; Li, S. M.; Ma, P. W.; Zhang, X. C.; Liu, Q. H.; Fu, R. W.; Wu, D. C. Adv. Mater. 2019, 31, 1802922.

[47] Liang, J. G.; Luo, Z.; Yan, Y.; Yuan, B. Mater. Rep. 2018, 32, 1779. (梁杰铬, 罗政, 问钰, 袁斌, 材料导报, 2018, 32, 1779.)

[48] Xu, Y. F.; Gao, L. N.; Shen, L.; Liu, Q. Q.; Zhu, Y. Y.; Liu, Q.; Li, L. S.; Kong, X. Q.; Lu, Y. F.; Wu, H. B. Matter 2020, 3, 1685.

[49] Cui, C. Y.; Yang, C. Y.; Eidson, N.; Chen, J.; Han, F. D.; Chen, L.; Luo, C.; Wang, P. F.; Fan, X. L.; Wang, C. S. Adv Mater. 2020, 32, e1906427.

[50] Shi, H. D.; Qin, J. Q.; Huang, K.; Lu, P. F.; Zhang, C. F.; Dong, Y. F.; Ye, M.; Liu, Z. M.; Wu, Z. S. Angew. Chem., Int. Ed. 2020, 59 12147.

(Cheng, B.) 